\title{
Arsphenamine jaundice and the recognition of instrument-borne virus infection
}

\author{
Philip P Mortimer
}

\begin{abstract}
Soon after its introduction in 1910, intravenous arsphenamine treatment for syphilis was found to be complicated by jaundice. The underlying cause, unsterile syringes and needles, was eventually recognised in the early 1940s, mainly through the efforts of British Army investigators. The infection most often transmitted was probably hepatitis B virus (HBV), but the high mortality in a few of the outbreaks of arsphenamine jaundice suggests that variants of $\mathrm{HBV}$, or other hepatitis viruses, were sometimes involved. Fifty years later, at a time when there are estimated to be over three hundred million carriers of $\mathrm{HBV}$ in the world and probably at least as many hepatitis $C$ virus carriers, and when the World Health Organisation estimates that there have been 17 million infections with human immunodeficiency virus, the lessons learnt around 1945 about the need to use sterile instruments and needles for all injections and venepunctures remain highly pertinent.
\end{abstract}

(Genitourin Med 1995;71:109-119)

Keywords: hepatitis; arsphenamine; history

Setting the scene

'The past can seem a burden to some, an irrelevance to be shuffled off leaving the present unencumbered ... for others the past is the parent of today and as such powerful, wise, instructive'. (Barbara Willard, English historical novelistdied 1994)

Only those who are in or close to retirement, or who have practised outside Western Europe and North America, will have had day to day experience of using non-disposable syringes and needles and of dealing with the difficulties of sterilising them. For those people the 1945 UK Medical Research Council (MRC) memorandum, "The sterilisation, use and care of syringes", which sought to prevent the needle-borne infections that had become so prevalent in the early 1940 s, was an important source of guidance. It failed, nevertheless, to insist on a sterile syringe for every injection, a serious error that had to be corrected in a second edition published in $1962 .^{2}$ This edition recommended "that a fresh sterile syringe must be used for each patient not only for intravenous but for all other kinds of injections". "Sterile" in this context meant either heating in an oven at $160^{\circ} \mathrm{C}$ for one hour, or auto- claving by steam under pressure, or boiling at $100^{\circ} \mathrm{C}$ for 5 minutes at least. The second edition of the memorandum also contains useful summaries of published outbreaks of infection due to contaminated syringes and needles. These demonstrate that the problem of jaundice was at its most widespread and persistent in association with intravenous treatment of syphilis with arsphenamine, though it arose in many other contexts.

The story of arsphenamine jaundice extends from the introduction of the drug in 1910 to its replacement by penicillin in the late 1940 s. It reflects contemporary limits to the understanding of virus infection and the absence during that era of a microbiological rationale for effective sterilisation procedures. It was widely believed at that time that to flush syringes several times with a phenolic disinfectant followed by distilled water would render them safe for re-use. Only from the 1950s was boiling of syringes and needles in a "steriliser" between patients generally recognised, and enforced, as the minimum safe procedure.

The purpose of this study is to show how the true cause of arsphenamine jaundice was revealed, to suggest which viruses were involved and to document how the study of these outbreaks has contributed to understanding of the natural history of viral hepatitis and current hygienic practice for syringes and needles and other instruments. The fact that these hygienic principles are still not always honoured may be said to justify a retrospective that draws attention to the pervasive and yet hard to recognise character of instrument transmitted viral hepatitis in the first half of this century.

Arsphenamine: a drug falsely accused

Syphilis was brought under control by three scientific advances made around 1905. The first was the discovery by Schaudinn and Hoffman of the causative organism, Spirochaeta pallida (now Treponema pallidum) which they visualised by dark ground microscopy in fluid collected from primary syphilitic lesions. The second was the Wasserman reaction, a serological test for syphilis that was diagnostic of active infection. The third was the synthesis of a curative drug, arsphenamine. Syphilis chemotherapy had its origin in investigations into the treatment with arsenicals of animal trypanosomiases which eventually bore fruit in the preparation, by Ehrlich and colleagues, of two relatively non toxic and highly effective arsenobenzol 
compounds "606" (salvarsan, arsphenamine), discovered in 1909, and "914" (neosalvarsan, neoarsphenamine), discovered in 1912 . During 1909 the Japanese scientist Hata, working with Ehrlich, showed that arsphenamine rapidly removed spirochaetes from experimental syphilitic lesions in rabbits, and once some brief animal and clinical trials had been completed without revealing ill effects this drug was quickly released for clinical use.

Arsphenamine was immediately recognised as far superior to mercurials for the treatment of syphilis and was within months in use throughout Europe. Grunbaum wrote of it in 1910 that "the results after the [single] injection
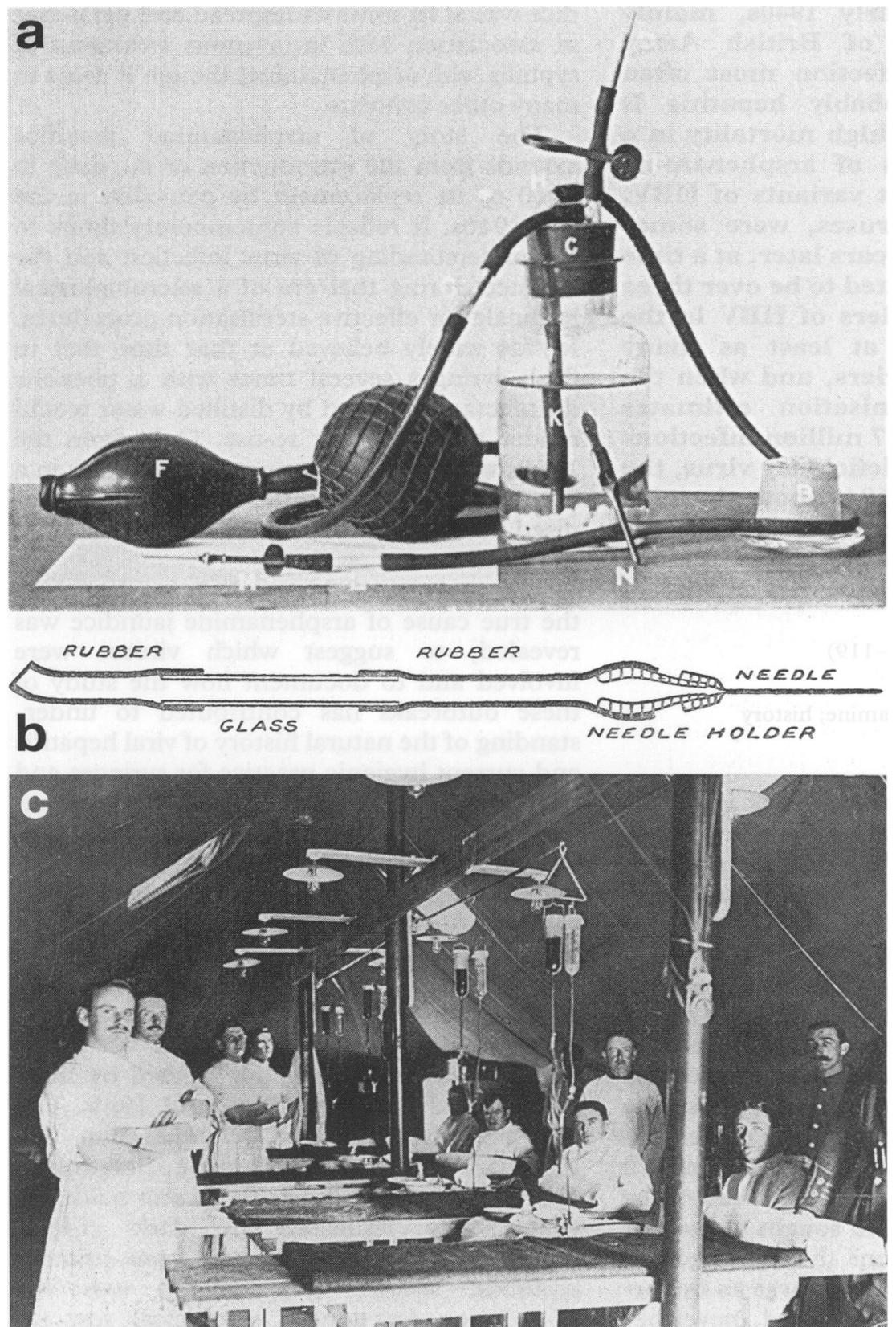

Figure 1 "The arrangement [for infusing arsphenamine] obviously did not preclude the possibility of regurgitation of blood into the apparatus and the transference of such blood to other patients"s. (a) Early apparatus for infusing arsphenamine (reproduced, with permission, from Syphilis from the Modern Standpoint, McIntosh and Fildes, pub. E Arnold, 1911. Note the glass "window" in the tubing just proximal to the cannula.

(b) Cross-section through needle holder and glass section of the tube used "so as to make sure that the needle was in the vein" (reference 5). (c) Medical officers and orderlies of the British Expeditionary Force posing as patients in a hut set up for giving arsphenamine infusions (reproduced, with permission, from the Quarterly fournal of Medicine, volume 10, 1916-17, published by Oxford University Press). are a little short of miraculous. Gummata, condylomata and rashes disappear extremely rapidly, whilst the Wasserman reaction usually becomes negative within five weeks." ${ }^{3}$ Harrison recorded that, on average, the primary syphilitic ulcer healed in 25 days compared with 66 days under mercury treatment. ${ }^{4}$ In more than $80 \%$ of cases the Wasserman reaction became neg ative by the end of a course of arsphenamine treatment for primary syphilis.

Arsphenamine is a yellow sparingly soluble powder which forms an unstable acidic solu? tion in water. When in use, between 1910 and the early 1920 s, it had to be freshly prepare and administered in large volume. At firs arsphenamine was often injected intramuscus larly, but this was painful and the virtuall painless intravenous route soon came to bo preferred. As fears about the potential toxicity of arsphenamine were allayed by early experience, it began to be given in increasing numbo bers of weekly intravenous infusions, each of $200-300 \mathrm{ml}$. To facilitate these infusions var $\vec{E}$ ous contrivances were used. The MRE Salvarsan Committee 2nd Report ${ }^{5}$ describes. in detail how, in one Army clinieg arsphenamine solution was fed by gravity int 8 a vein. "There was a short india-rubber tube at one end of which was a metal adapter for th attachment of the injection needle. The metatt adapter had a bulbous base over which the indias rubber tube fitted. The other end of this shokt india-rubber tube was fitted on to a piece of glasg tubing about three inches long, and this again int a long india-rubber tube leading from the receptos cle holding the solutions. When the needle was inserted into the vein the blood was allowed to rua back into the short glass tube so as to make sure that the needle was in the vein' [fig 1a, b]. 'The needle was changed for each case, but not the adapter or the short india-rubber or the glass tubes".

This description was written in relation to the Salvarsan Committee's investigation of a outbreak of needle transmitted malaria in syphilis patients, with nine deaths, that too $\bar{b}$ place at Portobello Barracks, Dublin, in 1917. It is equally relevant to the understanding of episodes of jaundice that at about the same time were being recognised as a complication of arsphenamine infusions. Yet the distin guished MRC committee, which could readilgo associate the use of such an apparatus with the transmission of malaria from patient patient, failed to realise that an infectious agent causing jaundice might be spread by the same means. Instead they suspected that arsphenamine was the cause of a delayed an idiosyncratic toxicity, as explained below.

Arsphenamine in the form of " 606 " was in general use in British army hospitals through out the 1914-18 War [fig 1, c], but in posi war civilian practice it soon gave way to trea ment with neoarsphenamine, ("914"). Thị compound was much more soluble than "606" and could simply be made up in a syringe in a volume of a few millilitres for immediate injection. Under various trade names, neoarsphenamine remained the mainstay of syphilis treatment from about 1920 
until the late 1940 s, when it was superseded by penicillin. Any minor chemical differences between these different trade formulations were probably insignificant, but the tendency to use longer and repeated courses once the administration of the drug was simplified was not. By the 1940 s as many as four successive courses of ten weekly injections were being given in some cases of syphilis, ${ }^{6}$ and the protracted nature of the treatment was undoubtedly a factor in increasing the incidence and possibly the severity of arsphenamine jaundice.

\section{Early reports of arsphenamine "toxicity": the} Cherry Hinton outbreak

The MRC set up its Salvarsan Committee in February 1918 to investigate the manufacture, biological testing and clinical administration of the drug. Concern had already been expressed about what seemed to be an unpredictable and sometimes severe toxicity. The committee reported that: "shortly after the introduction of arsphenamine it was observed that certain untoward symptoms occasionally followed its administration. The analysis of 39,377 military cases show $0.56 \%$ of jaundice. Before the era of salvarsan, benign jaundice was known to occur in a small number of cases of syphilis, particularly in the early stages of the disease, and its incidence has been estimated at 0.3 per cent. In military cases jaundice, and especially the severe type which has ended fatally in some instances, has been apt to occur in localised outbreaks. The committee have under consideration several of these outbreaks and notably one at Cherry Hinton Military hospital, Cambridge, which had a high proportion of fatalities". ${ }^{7}$

Cherry Hinton, once a village, is now a suburb of Cambridge. From 1916 it was the site of a temporary military hospital [fig 2] where, between April 1917 and April 1918, about 3000 men were treated for syphilis. Of these, $37(1 \cdot 23 \%)$ developed jaundice. This incidence was not unusually high but, almost uniquely, 15 of the 37 Cherry Hinton cases died of acute yellow atrophy of the liver. In a contemporary report of acute yellow atrophy associated with arsphenamine treatment McDonald, writing from Newcastle, had already described five post-mortems done on cases within two months. ${ }^{8} \mathrm{He}$ had previously seen only one case of acute yellow atrophy since 1898. He suggested "infection as being the new factor which, acting on livers previously damaged by syphilis, and possibly arsenic plus mercury, has completed the damage to the liver cells and allowed the autolysis of the tissue."

In 1922 the high mortality in these and some other outbreaks of arsphenamine jaundice led the MRC Salvarsan Committee to publish its second report. This focused on the complications of what had by then become universally recognised as a most effective treatment for syphilis. ${ }^{5}$ The weakness of McDonald's explanation for the acute yellow atrophy associated with arsphenamine was that he had backed all the horses: infection, syphilis itself and arsphenamine. The MRC Salvarsan Committee, by contrast, was seeking a single, unifying explanation for these deaths. They were at a loss to find one. They recognised the occurrence in the Cherry Hinton outbreak of early and late jaundice (fig 3) and they were able to draw the same distinction in other outbreaks. They identified acute yellow atrophy as "commonly the sequel of late jaundice, and clinically and pathologically indistinguishable from the same condition occurring in the known absence of syphilis". They noted that most late jaundice arose after the Wasserman reaction had become negative. They saw that the occurrence of jaundice was not related to the total dose of arsphenamine. They remarked on "the tendency of the cases of severe jaundice and liver atrophy in man to occur in the form of small outbreaks localised at one or another hospital and restricted in time to a few
Figure 2 Preparing for kit inspection at the Cherry Hinton Military Hospital, circa 1917 (courtesy of the Cambridge Collection,

Cambridgeshire Libraries).

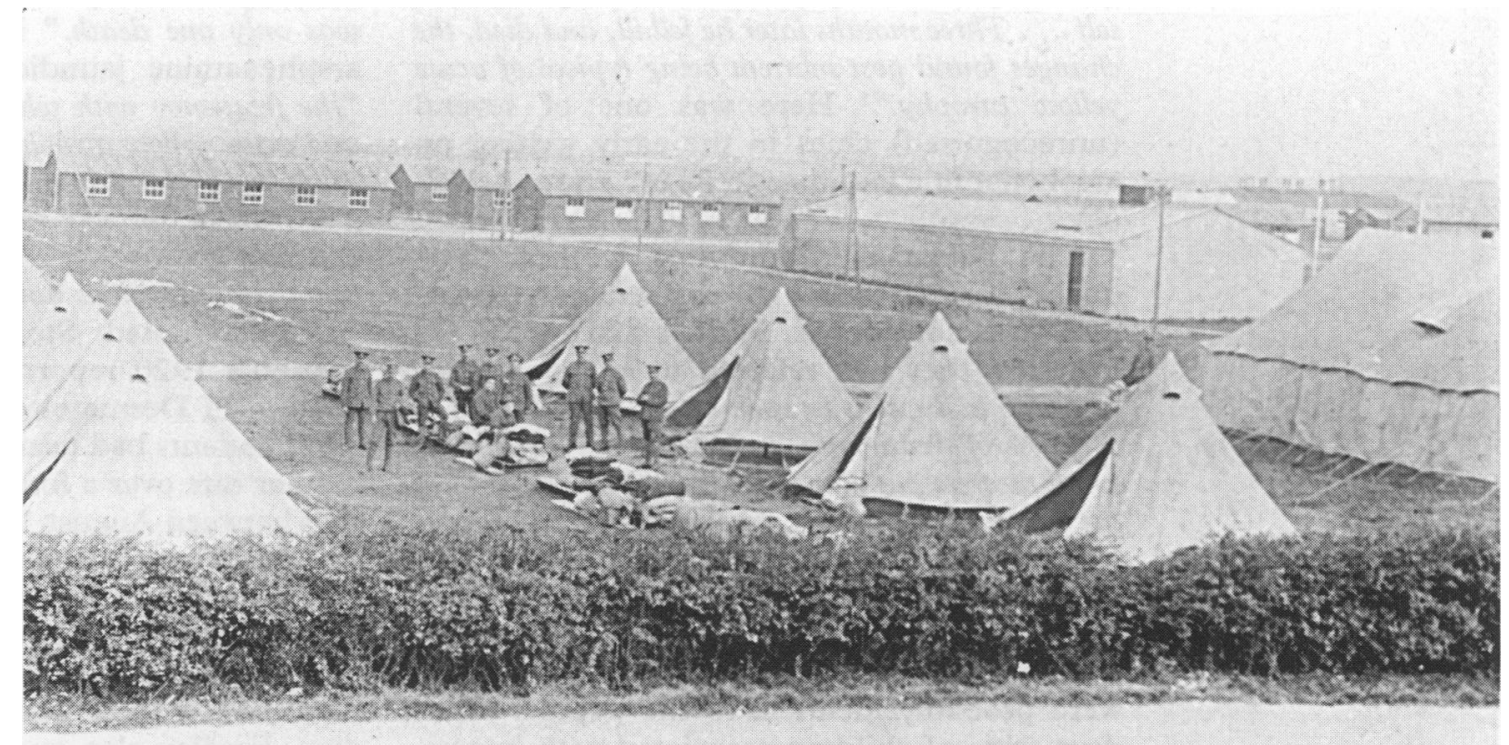




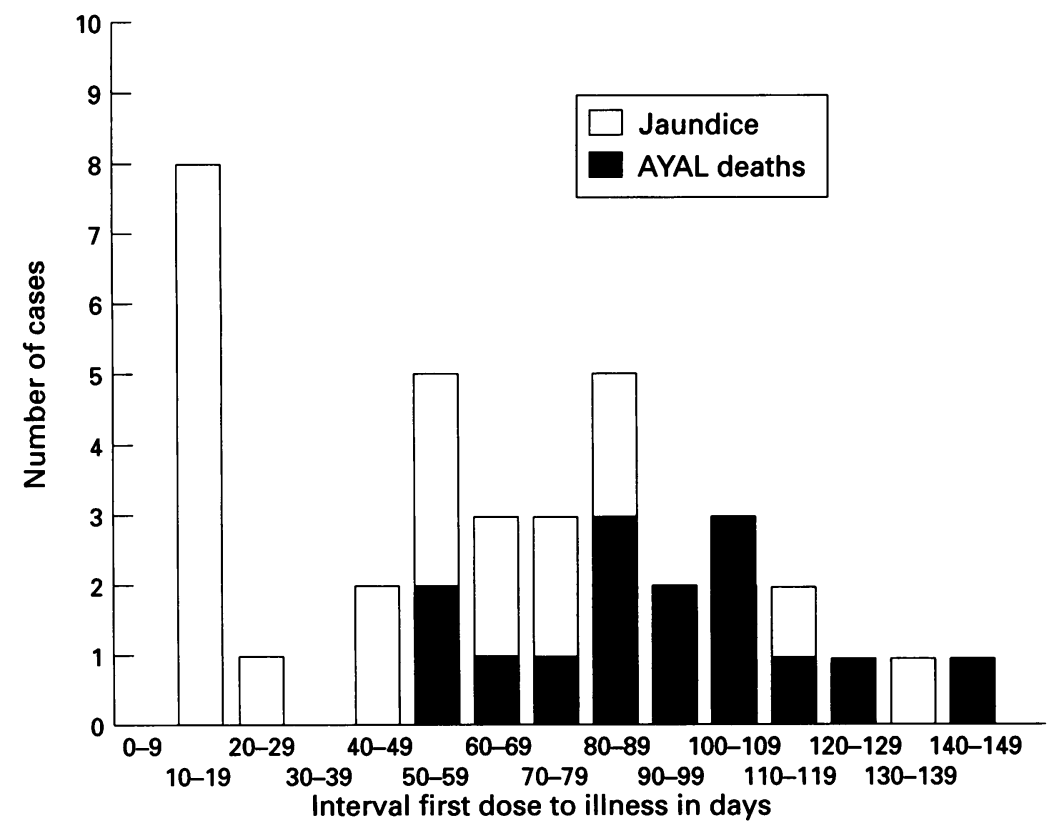

Figure 3 The Cherry Hinton outbreak of arsphenamine jaundice, April 1917-April 1918. There were 37 cases with 15 deaths in 2953 patients. Note the occurrence of "early" and "late" jaundice. why arsenotherapy patients developed jaundice and why some died from acute yellow atrophy. Its members had failed to recognise the implications of the delayed and non-recurrent nature of late arsphenamine jaundice, though both were features that argued against it being a toxic effect. They apparently did not seek secondary cases of jaundice and if there were any they failed, with the exception of the case of the young Ingolstadt pathologist, to report them. Their rather lame conclusion was that it was "probable that many of the ill effects of salvarsan may be attributed directly to its arsenical content ... in particular the effects on the liver... due to the chemical nature of the whole compound as an amino-phenol derivative, with the possibility that this type of poisonous action is dependent for its occurrence on the presence of adjuvant circumstances, of a nature as yet unknown."5

\section{Faundice as an infectious disease}

The main reason that the Salvarsan Committee could conclude that arsphenamine itself caused jaundice must surely be that no concept existed at the time of a viral aetiology for jaundice or acute yellow atrophy. In the late 1860 s the German pathologist Virchow had propounded the theory that "catarrhal" jaundice was the result of obstructive bacterial inflammation at the distal end of the common bile duct, and this view still prevailed in the early 1920 s though it was beginning to be challenged. " About 1931, GM Findlay read a paper Observations on Epidemic Catarrhal faundice to the Royal Society of Tropical Medicine and Hygiene and drew attention to the observations made in the 1920s which showed that epidemic catarrhal jaundice was a specific infection with an incubation period of 3-5 weeks, quite distinct from leptospiral jaundice. ${ }^{12}$ The idea of acute jaundice as a viral inflammation of the liver began to achieve recognition in Britain. "In this country epidemic catarrhal jaundice is an extremely benign condition," Findlay remarked. "Among records of more than 1000 cases there was only one death." $\mathrm{He}$ compared this with arsphenamine jaundice and concluded that "the frequency with which epidemics of jaundice and acute yellow atrophy have occurred in association with the administration of arsphenamine preparations strongly suggests that arsphenamine is acting synergically with some other agent of a living and infectious nature."

Findlay cited Stokes, Ruedermann and Lemon's 1920 report from the Mayo Clinic Section of Dermatology and Syphilis ${ }^{13}$ where 5200 patients had been treated for syphilis at a regular rate over a four year period. He noted that between August 1916 and July 1918 only six cases of arsphenamine jaundice had occurred, whereas between August 1918 and July 1920 there had been 64 cases. The sister in charge of the clinic Section and the husband of a patient had also contracted jaundice. Findlay also quoted $\operatorname{Todd}^{14}$ and others who reported the coincidence of arsphenamine jaundice with "catarrhal" jaundice in the community. He wrote: "the apparent arsphenamine jaundice and some of these were probably identical to the papular acrodermatitis of children associated with hepatitis B infection by Gianotti in $1973 . .^{10}$ Eventually, though, the Committee was forced to concede that it could not explain 
epidemics of acute yellow atrophy following arsphenamine treatment may possibly be explained by the action of the virus of catarrhal jaundice on a liver slightly damaged by arsphenamine."

It seems likely that some cases of "arsphenamine jaundice" were indeed due to community acquired viral hepatitis. In the Cherry Hinton outbreak, for instance, there was concurrent catarrhal jaundice in the local community which could have been the source of at least those cases of jaundice that arose in the hospital within four or five weeks of starting arsphenamine treatment (fig 3). It might also have been the cause of other cases. Yet the scale that the problem of arsphenamine jaundice was to reach in this and other centres went beyond what was seen in any local community outbreaks of catarrhal jaundice. Moreover acute yellow atrophy was frequent in some of the clinic outbreaks but very rare indeed in the community.

In Findlay's paper the emphasis is seen to move from toxicity towards virus infection of the liver as the explanation of the cause of arsphenamine jaundice: arsphenamine jaundice is attributed to community acquired epidemic catarrhal jaundice, with the higher morbidity being due to the toxic effect of the drug. This did not, however, explain why the jaundice in clinics occurred almost exclusively in those treated with arsphenamine, why the severity of arsphenamine jaundice was unrelated to the dose or duration of treatment ${ }^{15}$ and why the incubation period, which for "catarrhal jaundice" had recently been confirmed by Pickles to be close to four weeks ${ }^{16}$ was, in the case of arsphenamine jaundice, usually delayed for some weeks after the completion of a seven to ten week course of treatment. Nevertheless, as late as September 1942, the Lancet published an annotation that concluded "it is reasonable to suppose that many cases of post arsphenamine jaundice are due to virus infection, the resistance of the liver having been impaired by the toxic action of the arsphenamine. Epidemiological studies of infec-

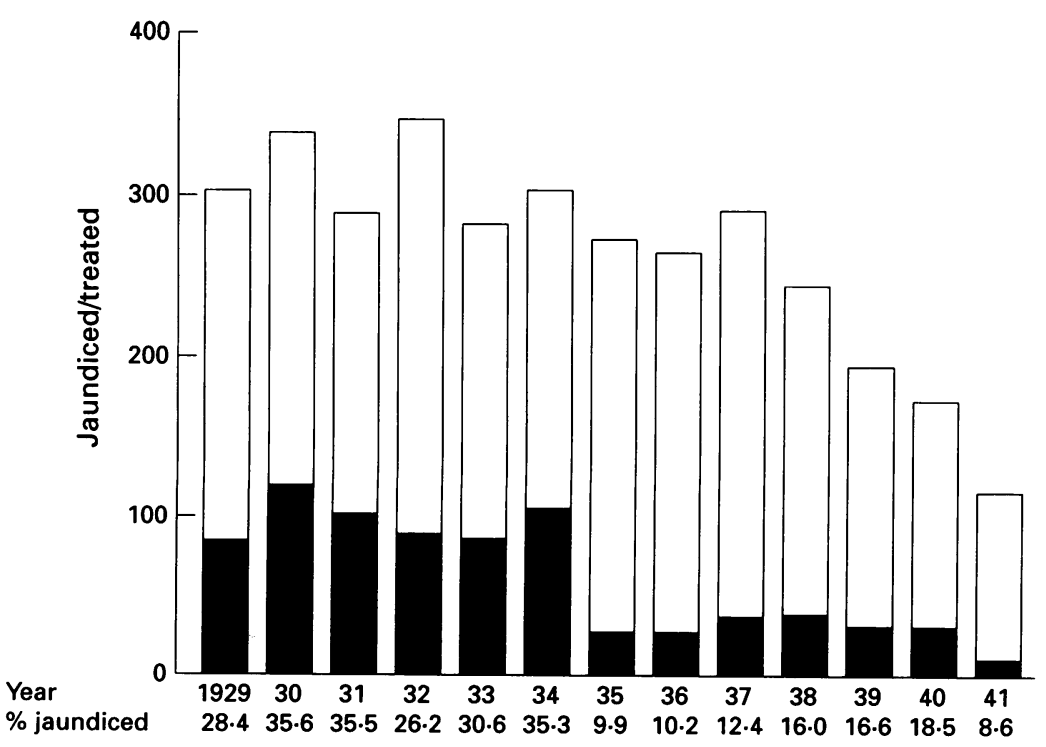

Figure 4 Incidence of jaundice before and after the introduction, in 1934, of boiling of syringes in the venereal diseases clinic of St Thomas' Hospital, London. tious hepatitis suggest that the disease is probably transmitted by droplet infection, that the incubation period is between three and six weeks and that patients are infective early in the disease and cease to be a danger to others within a week of the onset of symptoms." 17 The journal had thereby managed to combine an erroneous supposition about the route of spread of arsphenamine jaundice with an incubation period inconsistent with the long delays that often occurred between arsphenamine treatment and the onset of jaundice, and an unwarranted generalisation about infectivity.

Some months later, in July 1943, AnwylDavies published an account of observations made on arsphenamine jaundice at St Thomas' Hospital, London, between 1929 and $1941 .{ }^{18} \mathrm{He}$ referred to the Lancet annotation but also envisaged the possibility of "inoculation of the virus through faulty technique during treatment". The latter he regarded as "improbable as during 1934-35, when a neoarsphenamine preparation was used as routine treatment at St Thomas' Hospital, the incidence of jaundice reached such alarming proportions $(50 \cdot 18 \%)$ that increased aseptic precautions were taken by boiling the syringes before each injection without beneficial effect." How wrong he was! When Anwyl Davies' data are reviewed it is obvious that his intervention had been useful (fig 4), but evidence of its benefit was so blurred by the prolonged incubation period that it went unrecognised. Anwyl Davies' series included 776 cases of jaundice in 3422 patients receiving arsphenamine and seven deaths from acute yellow atrophy, a mortality similar to that in other contemporary reports. The willingness to tolerate over successive years an incidence of jaundice in excess of $30 \%$ during arsenotherapy at a London teaching hospital shows that in the inter-war years it was viewed as a relatively benign side-effect inseparable from arsphenamine treatment.

By the early years of the Second World War, however, arsphenamine jaundice had become so frequent and so debilitating to servicemen that it could no longer be ignored. Evidence was emerging from military clinics of a veritable epidemic among arsphenamine patients and this information, after some hesitation on the part of Army authorities, was eventually released for publication. Already, by 1942, the Lancet had spoken of " $a$ widespread impression that syphilitic treatment is too often being complicated by jaundice"17 and their earlier confusion of arsphenamine jaundice with epidemic catarrhal jaundice was fortunately not to be perpetuated for long. A connection between homologous blood exchanges and jaundice was first made, in the same journal, in $1943^{19}$ and the resemblance between homologous serum jaundice and arsphenamine jaundice was quickly recognised. A remedy for arsphenamine jaundice involving the use of sterile equipment was proposed and in 1944 it was shown that the unpredictable occurrence of jaundice after arsphenamine injections was due to an infectious agent whose transmission could be interrupted by sterile precautions. 
The penny drops: how the transmissibility of arsphenamine jaundice was revealed

In 1937 the first of a series of outbreaks of jaundice associated with the injection of biological products containing human serum or plasma had been described. These products included pooled convalescent and immune serum used to protect against measles and mumps, and serum stabilised yellow fever vaccine. ${ }^{20}$ The common thread running through these occurrences was identified by medical officers of the Ministry of Health in their 1943 memorandum on homologous serum jaundice. ${ }^{19}$ This classic paper analysed the effects of two batches of measles convalescent sera, one giving rise to 37 cases of jaundice at a median interval of 61 days and causing seven deaths apparently from acute yellow atrophy, the other giving rise to 11 cases at a median interval of 123 days and causing one death. The clinical features of homologous serum jaundice suggested "that differentiation from epidemic hepatitis should be possible and that erythema multiforme, stiff joints and splenic enlargement may in time be recognised as distinguishing points." The memorandum also documented, for the first time ever, jaundice following blood transfusion.

It was but a small conceptual step from the conclusion of the Ministry memorandum that the injection of human blood or blood products might after many weeks delay be followed by hepatitis to the realisation that individuals whose blood harboured an infectious agent might transmit it to others if syringes used on them were reused without effective disinfection. This notion had first been advanced when, in 1937 and 1938, some Irish children developed local tuberculous abscesses after immunisation against diphtheria. Bigger, Blacklock and Parish, working in Dublin, had investigated the ways by which injections of toxoid-antitoxin floccules might have become contaminated with Mycobacterium tuberculosis and these inquiries had drawn Professor Bigger's attention towards "the dangerous potentialities of syringes used for multiple inoculations. [These] led me to investigate the technique used in hospital VD departments". ${ }^{21}$ Having investigated syringe transmission of $M$. tuberculosis, Bigger went on to demonstrate experimentally, in a paper published in April 1943, how easily microorganisms might persist in used syringes. ${ }^{22} \mathrm{He}$ showed that a syringe seeded with staphylococci and flushed through up to five times, as done in a local venereal disease clinic between arsphenamine

Prevention of arsphenamine jaundice: studies that showed the superiority over flushing out of three different "sterilising" procedures for syringes

\begin{tabular}{|c|c|c|c|}
\hline Method & $\begin{array}{l}\text { Number of } \\
\text { patients }\end{array}$ & $\begin{array}{l}\text { Number (\%) } \\
\text { developing jaundice }\end{array}$ & Author \\
\hline $\begin{array}{l}\text { Syringe flushed out } \\
\text { Syringe heated to } 150-160^{\circ} \mathrm{C} \\
\text { for } 1 \text { hour }\end{array}$ & $\begin{array}{l}56 \\
18\end{array}$ & $\begin{aligned} 38(68) \\
1(5 \cdot 6)\end{aligned}$ & $\begin{array}{l}\text { Salaman, et al } \\
(1944, \text { Ref 26) }\end{array}$ \\
\hline $\begin{array}{l}\text { Syringe flushed out } \\
\text { Syringe soaked in antiseptic }\end{array}$ & $\begin{array}{r}200 \\
80\end{array}$ & $\begin{array}{r}100(50) \\
2(2 \cdot 5)\end{array}$ & $\begin{array}{l}\text { Sheehan } \\
\text { (1944, Ref 27) }\end{array}$ \\
\hline $\begin{array}{l}\text { Unspecified (?flushed out) } \\
\text { Boiled for } 20 \text { minutes } \\
\text { (the "Preston" technique) }\end{array}$ & $\begin{array}{l}154 \\
167\end{array}$ & $\begin{array}{l}66(43) \\
1(0 \cdot 6)\end{array}$ & $\begin{array}{l}\text { Laird } \\
(1947, \operatorname{Ref} 25)\end{array}$ \\
\hline
\end{tabular}

injections, remained contaminated. He concluded that a virus such as that of homologous serum jaundice "might . . . pass from patient to patient in clinics where similar techniques are used." He commented: "The use of a freshly boiled syringe for each patient is the most certain way of preventing this risk".

A month previously F.O. MacCallum had spoken at The Medical Society for the Study of the Venereal Diseases in London about his attempts to infect tissue cultures and chick embryos with serum from cases of arsphenamine jaundice. ${ }^{23}$ In the discussion that followed, the question of a route for human to human transmission of an agent responsible for arsphenamine jaundice arose. "Was it not possible" MacCallum suggested, "that some syringes might have a little blood from one man who was in a subclinical state of hepatitis, and if it only took 1/50th cc to cause jaundice in some cases [of homologous serum jaundice] might not that minute amount of blood going into another man be sufficient to produce his jaundice in anything from ten to fifteen weeks, which seemed to be the incubation period in the case of arsphenamine jaundice ... Perhaps a clue would be furnished if half a given number of patients were set aside and fresh syringes for each person used every time they came to the clinic while the other half were inoculated in the ordinary way. Then, after six months or so, it might be possible to find out whether there was any difference".

Though MacCallum's suggestion would quickly have furnished proof that syringes transmitted arsphenamine jaundice, no clinician came forward to conduct the experiment. The suggestion was, however, heard and Bigger's paper was read by many venereologists, including Laird. ${ }^{24} 25$ At the end of 1943 , "as the additional syringes necessary only then became available," Laird instituted the socalled Preston technique in his clinic-boiling of syringes for 20 minutes and a "no touch" routine for preparing, using and recycling syringes and needles. His excellent results in preventing arsphenamine jaundice and, using other sterilising procedures, those of Salaman and colleagues ${ }^{26}$ and Sheehan, ${ }^{27}$ are summarised in the table. In 1943 these three sets of authors had experienced jaundice rates of $37-55 \%$ in their clinics. In 1944, after syringes were routinely disinfected, the rates fell to $0 \cdot 6-4 \cdot 5 \%$. In another clinic where syringes had always been boiled between cases the problem of arsphenamine jaundice was hardly seen (four cases in 346 males treated in $4 \frac{1}{2}$ years; all four of these cases had also been treated elsewhere). ${ }^{28}$

In 1945 Laird read a paper on the prevention of arsphenamine jaundice to the Medical Society for the Study of the Venereal Diseases, and in the discussion that followed it was revealed how scarce syringes actually were. As Sheehan explained, "doctors ... were faced with the problem of giving dozens of intravenous injections a day using only a small number of syringes, and with the prospect of great difficulty in replacing any which are broken". ${ }^{24}$ Laird wrote "My own military centre possessed three syringes although 100 venepunctures daily for the 


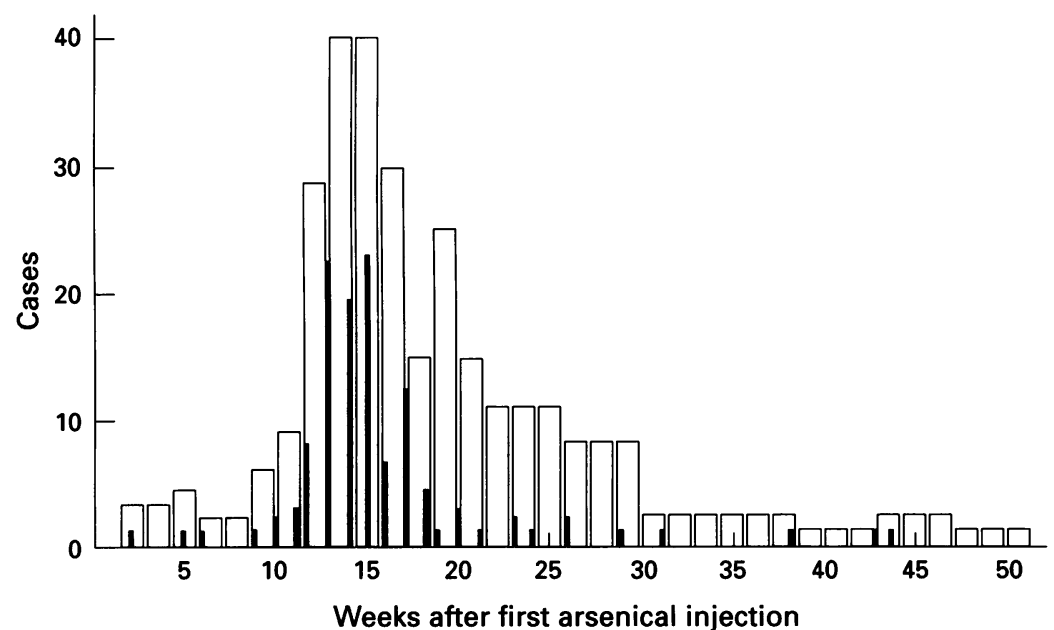

Figure 5 Two large series, published in 1944, showing the incubation period of arsphenamine jaundice. Compare fig 3 and note that exposure may have occurred at any one of 7-10 weekly injections. The incubation period may also have been influenced by the size of inoculum (see figure 6). syringe was boiled there was a risk of breakage, so how much simpler not to run that risk!

The long incubation periods associated with arsphenamine jaundice and their concordance with the incubation periods observed in cases of serum, yellow fever vaccine and transfusion associated jaundice disposed of the idea that the virus of epidemic catarrhal jaundice was the cause of arsphenamine jaundice in the minds of all but a few. ${ }^{11}$ Data from two large studies in $1944^{626}$ confirmed that the incubation periods for arsphenamine jaundice were much longer and more variable (fig 5) than for catarrhal jaundice ${ }^{16}$ and that they were similar to those for homologous serum jaundice as described in the Ministry of Health memorandum. It was thus gradually accepted that there was a second hepatitis virus to which the various clinical presentations of jaundice could be attributed. This virus was referred to in MacCallum's classification as hepatitis virus " $B$ " and in Beattie and Marshall's classification as hepatitis Y. ${ }^{6}$ When, in 1945, Truelove and Hogben analysed the occurrence of arsphenamine jaundice in allied troops in the Italian campaign they found that in 35 soldiers who gave a history of epidemic catarrhal hepatitis (that is, hepatitis A) and in 837 who did not, its incidence was almost identical $(34.3 \%$ and $36.3 \%$, respectively).$^{32}$ In other words, past infection with hepatitis A did not protect from infection with the agent of arsphenamine jaundice and therefore the two infections, $A$ and $\mathrm{B}$, were probably distinct. Venereologists were soon persuaded that arsphenamine jaundice could be prevented by improved syringe technique and that an agent transmitted in blood from patient to patient, distinct from the hepatitis A virus, was responsible for it. The primary cause of the jaundice was neither arsphenamine, nor syphilis itself, but a virus that was probably identical to that of homologous serum jaundice; and its transmission could be prevented by boiling syringes and needles between patients.

It was to be some time, however, before the good syringe practice promulgated by Laird and others was established in every clinic in Britain. Morton, writing in 1948, described the failures of sterilisation that took place "behind the medical officer's back" and attributed to them the continued high incidence $(20.7 \%-33.6 \%)$ of post arsphenamine jaundice in the clinic in which he worked..$^{33}$ With the persistence of such poor practice it is not surprising that, though the phenomenon of arsphenamine jaundice disappeared in the late 1940 s with the introduction of penicillin treatment for syphilis, penicillin injections were very soon associated with syringe hepatitis. ${ }^{34}$ Jaundice also complicated insulin, bismuth, gold, pentothal and sundry other injectable treatments as well as diagnostic investigations such as those of erythrocyte sedimentation rate and blood sugar level. ${ }^{2}$ As early as 1927 an outbreak of 34 cases of hepatitis in a diabetes clinic in Lund, Sweden, had been described and correctly associated with the use of an imperfectly disinfected lancet to 
collect blood for sugar estimations. This paper, published in German in a Scandinavian journal, ${ }^{35}$ was probably not widely read in Britain. $\mathrm{Had}$ it been, arsphenamine jaundice might never have reached the epidemic proportions it did in the early 1940 s.

\section{How else was the virus of "syringe" jaundice transmitted?}

The observations on arsphenamine jaundice contained early pointers to other routes of transmission of the implicated hepatitis virus or viruses. For instance, Sheehan reported six cases of jaundice in clinic orderlies and laboratory technicians. ${ }^{27}$ Other authors observed cases in the spouses of patients. MacCallum reported an instance in which the husband of a volunteer who had been injected subcutaneously with serum from a case of arsphenamine jaundice, himself developed jaundice 63 days later. ${ }^{36}$ MacCallum offered the opinion that the virus of arsphenamine jaundice could not "rely for its survival only on the accident of syringe transmission". ${ }^{37}$ The widespread use of blood products "may have caused naturally occurring cases from contact infection". Truelove and Hogben made the same point: "If we are driven to the conclusion that delayed serum hepatitis is a disease of which the only known vector is the physician and the only known organ by which the vector can transmit the infection agent is the syringe ... we are led to ask by what means the putative virus can persist endemic within a population not exposed to artificial methods of transmission". ${ }^{32}$ Yet no one at the time looked systematically for clinical evidence of transmission by non parenteral routes of the virus of "syringe" hepatitis.

There were, instead, human volunteer experiments in the 1940 s and early 1950 s to investigate the number of agents involved in viral hepatitis, their routes of transmission, the size of the infectious dose, the persistence
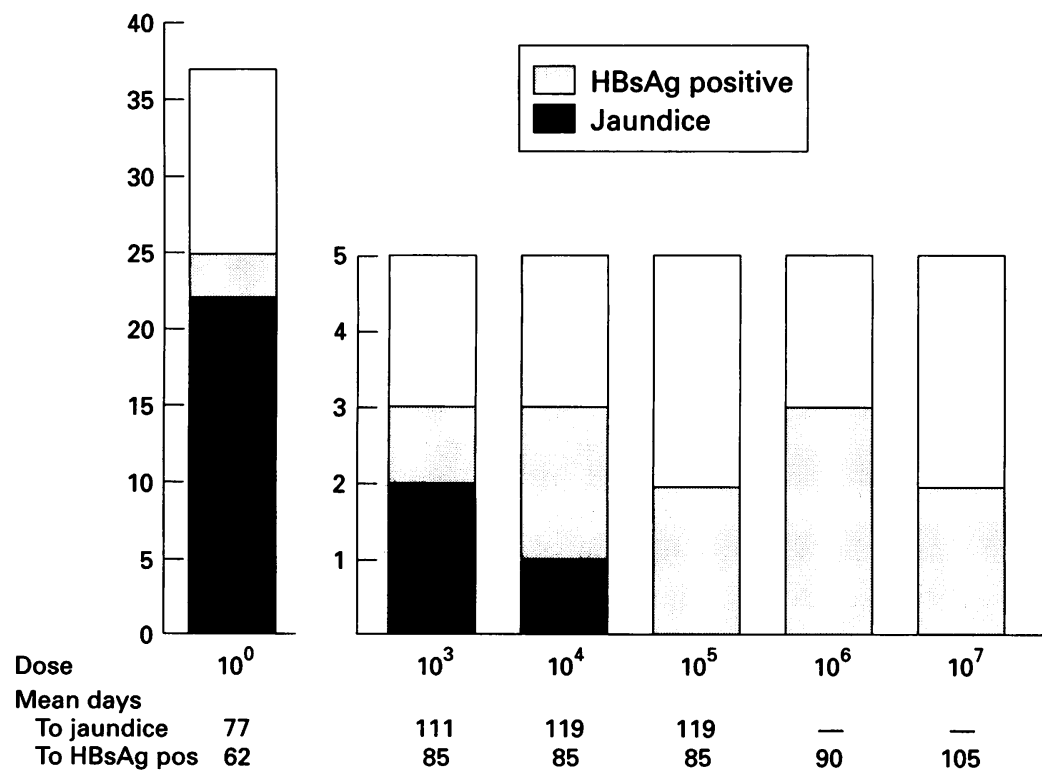

Figure 6 Appearance of hepatitis $B$ virus surface antigen and jaundice in volunteers inoculated with an icterogenic serum. Note the correlation of dose with interval to jaundice or, at higher dilutions of inoculum, with subclinical appearance of $\mathrm{HBs} \mathrm{Ag}$ (data taken from reference 36). of infectivity and the possible existence of sub-clinical and "carrier" cases. The earliest of these experiments, begun in 1943, involved specimens from arsphenamine jaundice patients, which were then readily available. Serum from these patients, and nasopharyngeal washings and faeces of volunteers inoculated with their serum, were used. Arsphenamine jaundice serum $(0.25-1.00 \mathrm{ml})$ caused hepatitis in 12 of 19 injected recipients in 41 to 80 days. When given by mouth the nasopharyngeal washings from these recipients were icterogenic in only 2 of 17 experiments and the faeces not at all (0 of 20 experiments). This work, reported in $1944,{ }^{37}$ was the first experimental demonstration of the limits of transmissibility of an agent present in arsphenamine jaundice serum. For the arsphenamine agent, unlike that of epidemic catarrhal jaundice, oral/faecal transmission was inefficient.

By 1950 transmission data had fully established the concept of $A$ and $B$ hepatitis viruses, oro-faecally and blood borne, respectively. Serum, nasopharyngeal washings, faeces and urine of cases of virus $A$ had all been found infectious when given by mouth; and serum from virus $B$ infections (homologous serum jaundice and syringe associated jaundice) had been shown to produce hepatitis in volunteers when injected subcutaneously. In addition, it had been reported from West Africa that when eight volunteers who had suffered syringe hepatitis were injected with a plasma pool derived from cases of post transfusion hepatitis none developed hepatitis. ${ }^{38}$ Two previously fit volunteers given the same icterogenic pool both developed hepatitis. This result indicated that "syringe" hepatitis and homologous serum jaundice could be due to the same virus, the former giving rise to immunity to the latter.

Further transmission studies on hepatitis virus B took place in the United States between 1951 and 1954 and were reanalysed by Barker and Murray in 1972 with the benefit of a test for hepatitis B surface ("Australia") antigen. ${ }^{39}$ (Here is one of a very few examples in this field in which individuals' stored specimens were successfully retested many years later using innovatory methods. Too often, in hepatitis research, sera preserved for future study have later proved to be irretrievable. ${ }^{40}$ ) The discovery of Australia antigen by Blumberg in the late 1960s had refreshed hepatitis studies "like an unexpected shower on desert soil", ${ }^{41}$ and Barker and Murray's application of a test for it showed that the icterogenic pool used in the 1950 s study contained hepatitis B virus (HBV). Their experiments also revealed the extraordinary infectiousness of the pool (a $10^{-7}$ dilution transmitted HBV), demonstrated the inverse relationship between dose and length of incubation period and illustrated the tendency for highly diluted inocula to lead only to subclinical infections (fig 6). It can readily be seen that these findings illuminate the otherwise baffling pattern of arsphenamine jaundice. 
Clinical observation meanwhile offered further clues to other modes of transmission of the syringe hepatitis/homologous serum jaundice agent(s). An analysis of British naval records by Ellis linked hepatitis in servicemen to preceding yellow fever and typhoid immunisation, smallpox vaccination, and tattooing. Ellis also recorded that "large numbers of isolated single cases occurred in crowded naval establishments. The occurrence of infective hepatitis was frequently associated with arsenotherapy hepatitis in the same establishments, suggestive of the possibility that both conditions were caused by the same infective agent". ${ }^{42}$ Ellis did not comment on the nature of the "isolated single cases" unassociated with immunisation or arsenotherapy and it is in retrospect surprising that he and the other investigators of the 1950s and 60s did not recognise a sexual route of transmission of the main icterogenic agent, which Barker and Murray's work indicates was HBV. This failure may partly be ascribed to the delayed or subclinical nature of most of the infections and partly to an unwillingness, especially in investigations of the armed forces, to acknowledge the existence of the homosexual contacts to which some of the cases were probably attributable. The first record of homosexual transmission of hepatitis B occurs, in 1970, in a comment at the end of a letter to the British Medical Journal by Cossart and Vahrman: "Several of our [HBs] antigen positive patients were practising homosexual males who had not had any injections; this suggests that the virus may be transmitted venereally, perhaps from mucous membrane to mucous membrane, or from abrasions exuding infected serum". ${ }^{43}$

Recognition of mother-baby transmission of HBV was even further delayed. As early as 1947 Truelove and Hogben ${ }^{32}$ had speculated that "there is nothing to preclude the possibility that human transmission lof the virus of serum hepatitis] could be accomplished through the medium of sexual generation by either one or both of the gametes, by transplacental spread to the foetus or by lactation". Yet an appreciation of the importance of vertical transmission of hepatitis $B$ virus in maintaining the prevalence of infection only developed in the mid 1970s. This provides a third example, together with needle borne and sexual transmission of hepatitis viruses, of the necessity for correct concepts to prevail before clinical and epidemiological evidence about the natural history of a virus/host interaction can fall into place. It may be noted in passing that it was by drawing on knowledge of hepatitis B virus transmission that took over 30 years to accumulate that epidemiologists studying a putative, homosexually spread, AIDS agent in 1981 were able rapidly to predict other probable routes of spread of that virus.

Were there viruses other than $H B V$ ?

Recent observations suggest that hepatitis $C$ virus (HCV) must regularly have been transmitted during arsenotherapy. Recent reports of the anti HCV status of intravenous drug users have shown even higher prevalences than for HBV antibodies and, by analogy, HCV infection may have been spread by arsenotherapy on just as large a scale as it has been more recently by illicit drug injection. ${ }^{44}$ However most acute infections with $\mathrm{HCV}$ are subclinical and it is impossible to tease out from contemporary observations on arsphenamine jaundice the traces of that virus. The most suggestive evidence that $\mathrm{HCV}$ was transmitted by contaminated syringes is a 1948 paper by Capps, et $a l^{45}$ which describes mostly subclinical hepatitis in 56 soldiers, 23 of whom became unwell 15-38 days after intramuscular administration by shared syringes of tetanus toxoid. Their liver function was closely studied by the bromosulphthalein retention test and 11 showed definite and six possible signs of liver inflammation. Only one soldier was clinically jaundiced. Now that specific serological tests that become positive within two months of exposure to $\mathrm{HCV}$ are widely available it is probably only a matter of time before an outbreak of $\mathrm{HCV}$ associated with contaminated instruments is recognised, even though these acute infections may be entirely subclinical.

Compared with the many cases of uncomplicated clinical hepatitis associated with arsphenamine treatment, the explanation for the cases of acute yellow atrophy of the liver, which were the focus of most contemporary concern, is more obscure. In retrospect they can mostly be ascribed to hepatitis $\mathrm{B}$ alone, but it is also possible to invoke as a cause concurrent infection, either HBV and delta agent (hepatitis D virus) or HBV and hepatitis C virus ( $\mathrm{HCV})$, or alternatively the selection of a virulent HBV variant as a result perhaps of reexposure in patients already infected with hepatitis B virus. In a recent outbreak of fulminant hepatitis in a dialysis unit there were probably repeated exposures to infection with a virulent $\mathrm{HBV}$ mutant. ${ }^{46}$ In an American survey of 28 cases of fulminant hepatitis B, 17 were associated with a single pre-core mutation. ${ }^{47}$ Of the entire 40 cases of fulminant hepatitis B in that series, only one was coinfected with HAV, two with HDV and two with $\mathrm{HCV}$.

The high mortality in some outbreaks of arsphenamine and other jaundice which, in their time, attracted so much attention, 5820 may thus not have been due to classic hepatitis $B$ virus infection. In large military ${ }^{7}$ and civil$\operatorname{ian}^{18}$ series of arsphenamine jaundice and in the immunisation in 1942 of about 50,000 US troops with contaminated yellow fever vaccine, ${ }^{48}$ this seemed to carry a mortality of only about $0 \cdot 3 \%$. By contrast, in one outbreak of arsphenamine jaundice it had been $41 \%$ and the outbreaks of jaundice associated with some pooled serum preparations were almost as fatal. ${ }^{40}$ To account for these gross discrepancies another factor, possibly concurrent exposure to hepatitis viruses from more than one source, must have been present where mortality was extraordinarily high.

Finally, in the case of arsphenamine jaundice, toxicity should not be wholly discounted as a factor that increased morbidity and 
mortality. Jaundice mostly occurred at an interval after the end of treatment, but when arsenotherapy did overlap the onset of jaundice, hepatitis was exacerbated: "if an injection was given after the urine turned dark, jaundice was precipitated within 48 hours. In such cases the jaundice was deep and the course of the disease prolonged" ${ }^{49}$ In identifying a hepatitis virus, almost certainly HBV, as the necessary cause of arsphenamine jaundice, the possible contribution of drug toxicity, which so dominated the thinking of early investigators, should not be ignored.

How is arsphenamine jaundice relevant today? If a comparison with the effects of contaminated yellow fever vaccine is valid, ${ }^{20} 50$ very few arsphenamine patients can have become HBV carriers. Arsphenamine treatment may therefore have made only a small contribution to the carriage and spread of $\mathrm{HBV}$. Nevertheless, the facts that arsenotherapy was used to treat a sexually transmitted disease, that the courses of treatment took many weeks to complete and were often repeated, and that the practices employed to decontaminate syringes in the interwar and early war years were, to use Bigger's telling phrase, "often perfunctory" 22 suggest that arsenotherapy offered many opportunities for HBV infection to be disseminated into the community. Sub-clinical infections with $\mathrm{HBV}$, and with $\mathrm{HCV}$, must have gone unrecognised, and transmissions to sexual partners and from mothers to infants must have occurred. Some of the patients who have presented over later decades with chronic hepatitis and cirrhosis probably owe their illnesses, directly or indirectly, to infection with hepatitis viruses during courses of arsphenamine injections given in the $1920 \mathrm{~s}$, 30 s and 40 s.

The arsphenamine jaundice epidemic of the early 1940s emphasises the continuing need to provide and use sterile equipment. In wartime Britain the supplies of syringes necessary to eliminate cross contamination were often inadequate and this was the primary cause of a national epidemic. In the intervening fifty years, virus transmissions analogous to arsphenamine jaundice have continued to be reported worldwide. In 1976, in localities in Sudan and Zaire joined by a trucking route, ebola virus infection was amplified to devastating effect by the use of unsterile syringes. ${ }^{50}$ More recently, in an outbreak in two hospitals in Elista in the former Soviet Union, over 90 children were similarly infected with human immunodeficiency virus (HIV). ${ }^{51}$ A few of these children transmitted the virus to their mothers. On transfer of some of these patients to hospitals in Rostov the same strain of HIV was introduced and spread by parenteral routes there. ${ }^{52}$ The use of unsterile syringes was largely responsible for over 2000 cases of AIDS in young Rumanian children, most of them in institutional care. To quote: "the source(s) of HIV infection were blood and blood products transfusions, needles and syringes commonly used repeatedly without being properly disinfected or sterilised, the treatment of mal- nourished children with whole blood to provide nutrients and multiple intramuscular injections instead of oral medication". ${ }^{53}$

At least three persistent and hazardous viraemias are now very prevalent worldwide: over three hundred million people carry HBV; probably as many or more carry $\mathrm{HCV}$; and (latest WHO estimate) seventeen million have acquired HIV. At the same time, in many parts of the world, syringes and needles, disposable and reusable, remain in short supply. They are sometimes inadequately decontaminated. They are frequently used to give inappropriate treatment, or appropriate treatment by inappropriate routes. The viruses that they may transmit from carriers to susceptible patients are generally distinguished by the absence of rapid clinical effects so that a follow up of months, or in the case of HCV and HIV several or more years, is necessary to reveal inadvertent transmissions. To follow up the whole range of percutaneous procedures in health care settings would require very considerable resources; to publish reports of the transmissions that are recognised arouses controversy and demands professional courage. It is therefore unrealistic to expect that there will ever be fully effective monitoring of the results of possible lapses of syringe and needle hygiene. Syringe-borne virus infection will always be a largely silent endemic and its elimination will depend firstly upon recognition of the phenomenon, then upon access, worldwide, to adequate supplies of sterile injection equipment and finally upon the will to use them correctly. Fifty years after the problem was first elucidated the same errors are still being committed, either through ignorance or indifference. As the modern American philosopher has remarked: "Those who do not learn the lessons of history are condemned to repeat it" (George Santayana).

I thank Mrs Anne Carroll, Miss Margaret Clennett, Dr Lena Grillner, Miss Amanda Midgley, Dr Eddie Taylor, Miss Lis Walsh, Mr John White and Dr HB Wyatt whose skills, help and knowledge have allowed me to prepare this article; also D Morag Timbury for her careful reading of the manuscript.

1 Medical Research Council War Memorandum no 15, 1945: The Sterilization, use and care of syringes.

2 Medical Research Council Memorandum no 41, 1962 The sterilization, use and care of syringes.

3 Martindale WH, Westcott WW. "Salvarsan" or "606": its Chemistry, Pharmacy and Therapeutics, London: HK Lewis, 1911:54-5.

4 Harrison LW. Critical review: the treatment of syphilis. $Q \mathcal{F}$ Med 1917;10:291-360.

5 Medical Research Council Special report series No 66 1922: Toxic effects following the employment of 1922. Toxic effects follo

6 Beattie J, Marshall J. The aetiology of post-arsphenamine jaundice. $B M F$ 1944;1:547-50.

Medical Research Council Special report series No 44 1919: Reports of the special committee upon the manufacture, biological testing, and clinical administration of salvarsan and of its substitutes.

$8 \mathrm{McDonald} \mathrm{S}$. Acute yellow atrophy in syphilis (a preliminary note). Lancet 1918;i:76-8.

9 Silbergleit H, Föckler. Ueber das Auftreten von Ikterus und akuter gelber Leberatrophie bei Syphilitikern im Anschluss an Neosalvarsanbehandlung. Ztschr f klin Med 1919;88:333 [quoted in reference 5].

10 Gianotti F. Papular acrodermatitis of childhood: an Australia antigen disease. Arch Dis Child 1973;48:794-9. McNee J. Infective Hepatitis: A problem of world health BMF 1952;i:1367-71.

12 Findlay GM, Dunlop JL, Brown HC. Observations on epidemic catarrhal jaundice. Trans Royal Soc Trop Med Hyg 1931;25:7-24.

13 Stokes JH, Ruedemann R, Leman WS. Epidemic infec- 
tious jaundice and its relation to the therapy of syphilis. Arch Intern Med 1920;26:521-43.

14 Todd AT. Post-salvarsan jaundice. Lancet 1921;i:632-4. 15 Wile UJ, Sams WM. A study of jaundice in syphilis: its relation to therapy. Am $\mathcal{F}$ Med Sci 1934;187:297-315.

16 Pickles WN. Catarrhal jaundice. Control of the Common Fevers 1941;19:304-12

17 Post-arsphenamine jaundice. Annotation, Lancet 1942;ii: 286-7.

18 Anwyl-Davies T. Post-arsenical jaundice and dermatitis: a survey of records from St Thomas' Hospital. F Roy Nav Med Serv 1943;29:153-69.

19 Homologous Serum Jaundice: special article. Lancet 1943;i:83-8.

20 Findlay GM, MacCallum FO. Acute hepatitis and yellow fever immunization. Trans $R$ Soc Trop Med Hyg 1937;31:297-308.

21 Bigger JW, Blacklock JWS, Parish HJ. Investigations and observations on inoculation technique. $B M \mathcal{F}$ 1940;i:79-84

22 Bigger JW. Jaundice in syphilitics under treatment: possible transmission of a virus. Lancet 1943;i:457-8.

23 Discussion following Anderson TE. Jaundice in Syphilitics. Br $\mathcal{F}$ Venereal Dis 1943;19:58-62.

24 Laird SM. The prevention of syringe-transmitted hepatitis. Br f Venereal Dis 1945;21:29-61.

25 Laird SM. Syringe transmitted hepatitis. Glasgow Med $\mathcal{F}$ 1947;28:199-219.

26 Salaman MH, King AJ, Williams DI, Nicol CS. Prevention of jaundice resulting from antisyphilitic treatment. Lancet 1944;ii:7-8.

27 Sheehan HL. Epidemiology of infective hepatitis. Lancet 1944;ii:8-11.

28 Climie H. Jaundice in syphilitics. Lancet 1944;ii:91.

29 Hackett CJ. Private medical practice and anti-yaws campaigns in South Eastern Nigeria. Tropical Doctor paigns in South.

30 Jacobson FW, in discussion of reference 24.

Mendelsohn K, Witts LJ. Transmission of infection during withdrawal of a blood. BMF 1945;1:625-6.

32 Truelove SV, Hogben L. A documentary study of jaundice associated with syphilis treatment and blood transfusion. Br F Soc Med 1947;i:18-32.

33 Morton RS. Syringe-transmitted jaundice: an inquiry and a plea. $B M \mathcal{F} 1948 ; 2: 938-9$.

34 Hughes RR. Post penicillin jaundice. BMF 1946;2:685-8.

35 Flaum A, Malmros H, Persson E. Eine nosocomiale Ikterus-Epidemie. Acta Med Scand 1926;suppl 1: 544-51.

36 MacCallum FO, McFarlan AM, Miles JAR, Pollock MR, Wilson C. Infective hepatitis: studies in East Anglia during the period 1943-47. Medical Research Council ing the period 1943-47. Medical

37 MacCallum FO, Bauer J. Homologous serum jaundice: transmission experiments with human volunteers. Lancet 1944;i:622-7.

38 Findlay GM. Infective hepatitis in West Africa-II syringetransmitted hepatitis. Bulletin of Ministry of Health 1945;32-9.

39 Barker LF, Murray R. Relationship of virus dose to incubation time of clinical hepatitis and time of appearance bation time of clinical hepatitis and time of appearance of hepatitis-ass

40 Cockburn WC, Harrington JA, Zeitlin RA, Morris D, Camps FE. Homologous serum hepatitis and measles prophylaxis. $B M \mathcal{F}$ 1951;ii:6-12.

41 Enders JF quoted by S. Krugman in Viral Hepatitis: overview and historical perspective. Yale $₹ \mathrm{Biol} \mathrm{Med}$ 1976;49:199-203.

42 Ellis FP. Infective hepatitis and arsenotherapy hepatitis as it occurred amongst naval personnel in Portsmouth during the 1939-45 War. F Hyg 1953;51:145-56.

43 Cossart YE, Vahrman J. Studies of Australia-SH antigen in sporadic viral hepatitis in London. BMF 1970;1:403-5.

44 Van der Hock JAR, van Haarstrecht, Goudsmit J, et al. Prevalence, incidence, and risk factors of hepatitis $C$ virus infection among drug users in Amsterdam. $尹$ Infect Dis 1990;162:823-6.

45 Capps RB, Sborov V, Scheiffley CS. A syringe-transmitted epidemic of infectious hepatitis. $\mathscr{F} A M A$ 1948;136: 819-24.

46 Oren D, Hershow RC, Ben-Porath E, et al. A common source outbreak of fulminant hepatitis B in a hospital. Ann Intern Med 1989;110:691-8.

47 Liang TJ, Hasegawn K, Munoz SJ, et al. Hepatitis B virus precore mutation and fulminant hepatitis in the United States. F Clin Invest 1994;93:550-5.

48 Seeff LB, Beebe GW, Hoofnagle $\mathrm{JH}$, et al. A serological follow-up of the 1942 epidemic of post-vaccination hepatitis in the United States Army. $N$ Engl $f$ Med 1987;316:965-70.

49 Damordaran K, Hartfall SJ. Infective hepatitis in the garrison of Malta. BMF 1944;ii:587-90.

50 Sawyer WA, Meyer KF, Eaton MD, et al. Jaundice in army personnel in the western region from the US and its relation to vaccination against yellow fever. $A n \mathcal{F} H y g$ 1944;40:35-107.

51 Breman JG, et al. The epidemiology of ebola haemorrhagic fever in Zaire, in Ebola SR Pattyn, ed. Virus Haemorrhagic Fever. Elsevier/North-Holland Biomedical Press 1978:103-11.

52 Bobkov A, Garaev MM, Alla Rzhaninova G, et al. Molecular epidemiology of HIV-1 in the former Soviet Union: analysis of env V3 sequences and their correlation with epidemiologic data. AIDS 1994;8:619-24.

53 Patrascu IV, Dumitrescu O. The epidemic of human immunodeficiency virus infection in Romanian children. AIDS Res Hum Retroviruses 1993;9:99-104. 